\title{
Glucocorticoid Exposure in Late Gestation Permanently Programs Rat Hepatic Phosphoenolpyruvate Carboxykinase and Glucocorticoid Receptor Expression and Causes Glucose Intolerance in Adult Offspring
}

\author{
Moffat J. Nyirenda, Robert S. Lindsay, Chris J. Kenyon, Ann Burchell, ${ }^{\star}$ and Jonathan R. Seckl \\ Molecular Endocrinology Laboratory, Molecular Medicine Centre, University of Edinburgh, Western General Hospital, Edinburgh EH4 \\ $2 X U$, United Kingdom; and *Department of Obstetrics and Gynaecology, Ninewells Hospital and Medical School, University of Dundee, \\ Dundee DD1 9SY, United Kingdom
}

\begin{abstract}
Low birth weight in humans is predictive of insulin resistance and diabetes in adult life. The molecular mechanisms underlying this link are unknown but fetal exposure to excess glucocorticoids has been implicated. The fetus is normally protected from the higher maternal levels of glucocorticoids by feto-placental $11 \beta$-hydroxysteroid dehydrogenase type-2 (11ß-HSD2) which inactivates glucocorticoids. We have shown previously that inhibiting $11 \beta-H S D 2$ throughout pregnancy in rats reduces birth weight and causes hyperglycemia in the adult offspring. We now show that dexamethasone (a poor substrate for $11 \beta-H S D 2$ ) administered to pregnant rats selectively in the last week of pregnancy reduces birth weight by $10 \%(P<0.05)$, and produces adult fasting hyperglycemia (treated $5.3 \pm 0.3$; control $4.3 \pm 0.2 \mathrm{mmol} /$ liter, $P=0.04$ ), reactive hyperglycemia (treated $8.7 \pm 0.4$; control $7.5 \pm 0.2 \mathrm{mmol} /$ liter, $P=0.03$ ), and hyperinsulinemia (treated $6.1 \pm 0.4$; control $3.8 \pm 0.5 \mathrm{ng} / \mathrm{ml}, P=0.01$ ) on oral glucose loading. In the adult offspring of rats exposed to dexamethasone in late pregnancy, hepatic expression of glucocorticoid receptor (GR) mRNA and phosphoenolpyruvate carboxykinase (PEPCK) mRNA (and activity) are increased by $25 \%(P=0.01)$ and $60 \%(P<0.01)$, respectively, while other liver enzymes (glucose-6-phosphatase, glucokinase, and 11ß-hydroxysteroid dehydrogenase type-1) are unaltered. In contrast dexamethasone, when given in the first or second week of gestation, has no effect on offspring insulin/glucose responses or hepatic PEPCK and GR expression. The increased hepatic GR expression may be crucial, since rats exposed to dexamethasone in utero showed potentiated glucose responses to exogenous corticosterone. These observations suggest that excessive glucocorticoid exposure late in pregnancy predisposes the offspring to glucose intolerance in adulthood. Programmed hepatic PEPCK overexpression, perhaps mediated by increased GR, may
\end{abstract}

Address correspondence to Dr. Moffat J. Nyirenda, Molecular Endocrinology Laboratory, Molecular Medicine Centre, University of Edinburgh, Western General Hospital, Edinburgh EH4 2XU UK. Phone: 44-131-6511026; FAX: 44-131-6511085; E-mail: mn@srv0. med.ed.ac.uk

Received for publication 21 August 1997 and accepted in revised form 12 March 1998.

J. Clin. Invest.

(C) The American Society for Clinical Investigation, Inc. 0021-9738/98/05/2174/08 \$2.00

Volume 101, Number 10, May 1998, 2174-2181

http://www.jci.org promote this process by increasing gluconeogenesis. $(J$. Clin. Invest. 1998. 101:2174-2181.) Key words: glucocorticoids - 11ß-hydroxysteroid dehydrogenase - birth weight • gluconeogenesis • non-insulin-dependent diabetes mellitus

\section{Introduction}

Increasing epidemiological evidence in humans suggests a key role for early life events in the development of cardiovascular and metabolic disorders $(1,2)$. In particular, low birth weight is strongly predictive of hypertension (3), glucose intolerance (4), non-insulin-dependent diabetes mellitus (NIDDM) $)^{1}(5)$, and death from ischemic heart disease $(1,2)$ in adult life. The association between birth weight and adult disease is independent of the classical life-style risk factors such as adult weight, social class, smoking, alcohol, and lack of exercise (1). Furthermore, these data reflect a continuous relationship representing birth weights within the normal range, not just severely undersized babies (1). These findings have led to the fetal origins hypothesis which suggests that environmental factors contributing to the pathogenesis of cardiovascular and metabolic diseases act, in part, in utero (6); thus, an adverse intrauterine environment would program or imprint the development of fetal tissues and organs, permanently determining responses, producing later dysfunction and disease. The individual organ system affected is determined by its unique vulnerability, based on the timing of the exposure and the systems developing during that time window (7).

The mechanisms linking intrauterine growth retardation and later disease are poorly defined. Recently, we provided evidence that excessive exposure of the fetus to maternal glucocorticoids might explain the link between low birth weight and subsequent glucose intolerance (8) and hypertension (9). Glucocorticoids have well characterized effects on blood pressure and glucose metabolism in the adult (10), and administration during pregnancy is known to reduce birth weight in humans and animals (11). Moreover, fetal cortisol levels are elevated in human intrauterine growth retardation (12). Steroid hormones are also involved in the development and maturation of various fetal and postnatal organ systems $(13,14)$, and administration in the perinatal period has been shown to produce permanent programming effects. Neonatal androgen administration, for example, permanently influences hepatic

1. Abbreviations used in this paper: $11 \beta-\mathrm{HSD} 2,11 \beta$-hydroxysteroid dehydrogenase type 2; DEX WK, dexamethasone-treated in week of gestation; GR, glucocorticoid receptor; IGF, insulin-like growth factor; IGFBP-1, insulin-like growth factor binding protein-1; NIDDM, non-insulin-dependent diabetes mellitus; PEPCK, phosphoenolpyruvate carboxykinase; pv/pp, perivenous-to-periportal ratio. 
metabolic pathways and sexual behavior $(15,16)$, while perinatal glucocorticoids permanently affect the hypothalamic-pituitary-adrenal axis response to stress $(17,18)$. Glucocorticoids, which act via nuclear glucocorticoid receptors (GR) to regulate target gene transcription, might act in several ways in a developing animal to provoke later abnormalities in glucose metabolism. Several important hepatic processes, including many enzymes controlling the production and fate of metabolic fuels, are regulated by glucocorticoids. Phosphoenolpyruvate carboxykinase (PEPCK), a key enzyme in gluconeogenesis and an important target gene in NIDDM, is under potent glucocorticoid regulation (19).

The fetus is normally protected from the substantially (5 to 10 times) higher maternal levels of glucocorticoids by placental $11 \beta$-hydroxysteroid dehydrogenase type-2 (11ß-HSD2). This enzyme catalyzes the rapid conversion of physiologically active glucocorticoids (cortisol in humans, corticosterone in rats) to inert 11-keto products (cortisone and 11-dehydrocorticosterone, respectively) $(20,21)$. The activity of $11 \beta-H S D 2$ in the placenta correlates with birth weight (22). Recently, we have shown that administration of carbenoxolone (a potent inhibitor of 11 $\beta$-HSD2) to rats throughout gestation reduces birth weight and predisposes the offspring to hyperglycemia later in life (7). To test that this effect of carbenoxolone was produced by exposing the fetus to raised levels of glucocorticoids rather than less specific effects on other enzymes (such as 11 $\beta$-HSD1, a reductase enzyme which amplifies glucocorticoid action by regenerating active 11-hydroxy forms from inert 11-keto steroids), we used dexamethasone, a synthetic glucocorticoid which is a poor substrate for $11 \beta$-HSD2 (20). Thus, the goals of these studies were: $(a)$ to examine whether exposure to excess glucocorticoids during intrauterine development permanently programs abnormal glucose metabolism in the offspring, $(b)$ to determine the critical prenatal period(s) when glucocorticoids alter glucose metabolism, and (c) to examine the effects of prenatal glucocorticoids upon gene expression and activity of key enzymes involved in hepatic glucose metabolism and glucocorticoid action.

\section{Methods}

Animals. Female Wistar rats (200-250 g; Harlan UK Ltd., Bicester, UK) were maintained under conditions of controlled lighting (lights on 7:00 a.m. to 7:00 p.m.) and temperature $\left(22^{\circ} \mathrm{C}\right)$ and allowed free access to food (standard rat chow; $56.3 \%$ carbohydrate, $18.3 \%$ protein, $0.7 \% \mathrm{NaCl}$; Bruce Smith and Smart Scotland Ltd. Edinburgh) and tap water. The rats were time-mated and divided into four treatment groups (five females per group). Dexamethasone $(100 \mu \mathrm{g} / \mathrm{kg}$ per $\mathrm{d}$, dissolved in $4 \%$ ethanol- $0.9 \%$ saline, $200 \mu \mathrm{g} / \mathrm{ml}$ ) was given subcutaneously during the first (dexamethasone-treated in week of gestation [DEX WK] 1), DEX WK2, or DEX WK3, with vehicle injections in other weeks; a control group received an injection of vehicle alone throughout pregnancy (Control). On day 19 of pregnancy, maternal tail tip blood samples were collected to determine plasma glucose. At birth, the offspring were weighed. Male offspring, selected at random from each litter, were used in all subsequent experiments.

Oral glucose tolerance test. The offspring underwent an oral glucose tolerance test at $6 \mathrm{mo}$. Animals were fasted overnight and tests were started between 8:30 and 9:00 a.m. the following morning. An oral glucose load of $2 \mathrm{~g} / \mathrm{kg}$ was given by gavage and tail tip samples were collected in heparinized Eppendorf tubes at 0, 30, and $120 \mathrm{~min}$. Plasma was stored at $-20^{\circ} \mathrm{C}$.

Glucose was determined by the enzymatic (hexokinase) method using a glucose assay kit supplied by Sigma Chemical Co. (Poole, UK). The intraassay and interassay coefficients of variation were $<2 \%$. Insulin was measured by radioimmunoassay (rat insulin $\left[{ }^{125} \mathrm{I}\right]$ assay system; Amersham International, Buckinghamshire, UK). The intraassay and interassay coefficients of variation were $<10$ and $<15 \%$, respectively.

Corticosterone implants. At $5 \mathrm{mo}$, blood samples were collected by tail tipping to determine basal (8:30 a.m.) plasma corticosterone levels. Corticosterone was measured by specific radioimmunoassay, as described by MacPhee et al. (23). To determine the effect of exogenous corticosterone on blood glucose concentration, four pellets of corticosterone acetate $(250 \mu \mathrm{g} / \mathrm{d}$ corticosterone $)$ were given subcutaneously under halothane anesthesia (controls were sham operated). Fasting blood glucose was measured $3 \mathrm{~d}$ after pellets were inserted. After a week, animals were fasted overnight and, after decapitation, their livers removed for GR binding studies and mRNA expression.

$G R$ binding studies. Cytosol was prepared from fragments of excised livers for dexamethasone and corticosterone binding studies, as described previously (24). Briefly each liver sample was homogenized in $10 \mathrm{mM}$ Tris- $\mathrm{HCl}$ buffer ( $\mathrm{pH} 7.4$ ) containing $2 \mathrm{mM}$ DTT, $1.5 \mathrm{mM}$ EDTA, $0.1 \mathrm{M}$ sodium molybdate, and $10 \%$ glycerol. After centrifugation $\left(4^{\circ} \mathrm{C}\right)$ at 20,000 and $105,000 \mathrm{~g}$ for 20 and $60 \mathrm{~min}$, respectively, the protein content was adjusted to $4 \mathrm{mg} / \mathrm{ml}$. Aliquots $(50 \mu \mathrm{l})$ of liver cystol were incubated for $16 \mathrm{~h}$ at $4^{\circ} \mathrm{C}$ in buffer with $1.5 \mathrm{nM}\left[{ }^{3} \mathrm{H}\right]$ dexamethasone (Amersham International) and various concentrations of either nonradioactive dexamethasone or corticosterone $(0.316 \mathrm{nM}-$ $100 \mu \mathrm{M})$. Free and bound radioactivity were separated with dextrancoated charcoal (5 g/liter charcoal and $1 \mathrm{~g} /$ liter dextran T70 in buffer) and bound radioactivity was counted in a liquid scintillation spectrometer (Wallac, Crownhill, UK). Binding constants for dexamethasone and corticosterone were calculated from homologous and heterologous competition curves.

Enzyme activity. Fed animals were killed by decapitation between 9:00 and 10:00 a.m. and livers were removed immediately. 10\% (wt/vol) fresh liver homogenates were prepared at $0^{\circ} \mathrm{C}$ in medium containing $250 \mathrm{mM}$ sucrose and $5 \mathrm{mM}$ Hepes (pH 7.4). Homogenates were centrifuged at 3,600 $\mathrm{g}$ for $10 \mathrm{~min}$ to sediment intact cells. The supernatant fractions were further centrifuged at $130,000 \mathrm{~g}$ for $30 \mathrm{~min}$. The resulting supernatant (cytosol) was collected and stored at $-70^{\circ} \mathrm{C}$ for PEPCK and glucokinase assay. The pellet (microsomal fraction) was resuspended in buffer and stored at $-70^{\circ} \mathrm{C}$ for glucose-6-phosphate assay. Protein content of the preparations was determined by the Peterson method (25). PEPCK activity was assayed at $30^{\circ} \mathrm{C}$ by coupling the formation of oxalacetate with NADH oxidation in the presence of excess malate dehydrogenase (Boehringer Mannheim UK, Lewes, UK), as described by Petrescu et al. (26). The reaction mixture ( $1 \mathrm{ml}$ final volume) contained $50 \mathrm{mM}$ Hepes ( $\mathrm{pH} 6.5$ ), $50 \mathrm{mM}$ sodium bicarbonate, $1 \mathrm{mM} \mathrm{MnCl} 2,0.25 \mathrm{mM}$ NADH, $1 \mathrm{mM}$ phosphoenolpyruvate, $1.5 \mathrm{U}$ malate dehydrogenase, and $100 \mu \mathrm{l}$ of liver cytosolic preparation. The reaction was initiated with $0.15 \mathrm{mM}$ deoxy-GDP and the decrease in absorbance at $340 \mathrm{~nm}$ was followed for $5 \mathrm{~min}$. A reaction mixture lacking bicarbonate was used as control. Glucokinase was assayed using a continuous spectrometric method adopted from Davidson and Arion (27). The assay medium contained $50 \mathrm{mM}$ sodium Hepes, $100 \mathrm{mM} \mathrm{KCl}, 7.5 \mathrm{mM} \mathrm{MgCl}_{2}, 5 \mathrm{mM}$ ATP, $2.5 \mathrm{mM}$ DTT, $100 \mathrm{mM}$ glucose, $0.5 \mathrm{mM} \mathrm{NAD}^{+}$, and $1 \mathrm{U}$ of glucose-6-phosphate dehydrogenase (Sigma Chemical Co.). The activity of $0.01 \mathrm{ml}$ of cytosolic preparation was assayed in a final volume of $1 \mathrm{ml}$. The reaction was initiated by addition of ATP and the rate of $\mathrm{NAD}^{+}$reduction was recorded at $340 \mathrm{~nm}$. Control medium lacked ATP. Glucose6-phosphatase activity (in intact and disrupted microsomes) was assayed kinetically as described previously (28).

RNA probes. All restriction enzymes and RNA polymerases were obtained from Promega UK Ltd. (Southampton, UK). A 360-bp fragment derived from the coding region of rat PEPCK CDNA was generated by PCR using two primers (5' AGCTGCATAATGGTCTGG 3' and 5' GAACCTGGCGTTGAATGC 3'), and cloned into the pGEM-T easy vector (Promega UK Ltd.). Fidelity of amplifi- 
cation was confirmed by sequencing. The complementary antisense RNA strand was generated by SP6 RNA polymerase after NcoI linearization of the vector. Noncomplementary sense strand was transcribed by T7 RNA polymerase from SacI-linearized vector. GR templates were made from a 674-bp fragment of rat GR cDNA subcloned into pGEM3 (29). The sense strand was transcribed using SP6 RNA polymerase whereas the antisense strand was obtained from T7 RNA polymerase transcription. The $11 \beta-H S D 1$ antisense template was transcribed by $\mathrm{T} 3$ polymerization from pBluescript vector containing a 1.2-kb 11ß-HSD1 cDNA insert (30); T7 RNA polymerase was used to make the sense transcript. Radioactive probes were synthesized by incubating the appropriate RNA polymerase $(15 \mathrm{U})$ with $0.5 \mu \mathrm{g}$ of linearizd plasmid, $1 \times$ transcription buffer, $10 \mathrm{mM}$ DTT, $3 \mathrm{mM} \mathrm{ATP/}$ GTP/CTP, $200 \mu \mathrm{Ci}\left[\alpha{ }^{35}\right.$ S $]$ UTP (Amersham International), and $4 \mathrm{U}$ RNase inhibitor in a total volume of $10 \mu \mathrm{l}$ for $1 \mathrm{~h}$ at $37^{\circ} \mathrm{C}$ (or $40^{\circ} \mathrm{C}$ for SP6 RNA polymerase). $10 \mu \mathrm{l}$ of $0.1 \mathrm{U}$ of DNase 1 in $1 \times$ transcription buffer was added to the mixture and incubated for further 10 $\mathrm{min}$. Unincorporated nucleotides were removed by running the probe through a Sephadex G-50 column (Pharmacia Biotech, St. Albans, UK).

In situ hybridization. Livers were removed after decapitation and fragments quickly frozen in liquid nitrogen and stored at $-70^{\circ} \mathrm{C}$. In situ hybridization was performed as described previously (31). In brief, cryostat sections $(10 \mu \mathrm{m})$ were mounted on poly-L-lysinecoated slides and fixed for $10 \mathrm{~min}$ in $4 \%$ paraformaldehyde solution in $0.1 \mathrm{M}$ phosphate buffer $(\mathrm{pH} \mathrm{7.4)}$ ) and washed three times in $2 \times$ SSC. Antisense transcripts were diluted in hybridization buffer to $5 \times 10^{6} \mathrm{cpm} / \mu \mathrm{l}$. The hybridization mixture contained $0.5 \mathrm{M} \mathrm{NaCl}$, $0.01 \mathrm{M}$ Tris, $1 \mathrm{mM}$ EDTA, $10 \mathrm{mM}$ DTT, $10 \%$ dextran sulphate, $1 \times$ Denhardt's solution, $2 \mu \mathrm{g} / \mathrm{ml}$ herring testis DNA, $0.125 \mathrm{mg} / \mathrm{ml}$ yeast tRNA, and $50 \%(\mathrm{vol} / \mathrm{vol})$ deionized formamide. Hybridization was carried out overnight at $55^{\circ} \mathrm{C}$ in a chamber humidified with $50 \%$ deionized formamide/4× SSC. After washes (three times, room temperature) in $2 \times \mathrm{SSC}$, the sections were treated with $30 \mu \mathrm{g} / \mathrm{ml}$ bovine pancreatic RNase A (Boehringer Mannheim UK) in buffer containing $0.5 \mathrm{M} \mathrm{NaCl}, 0.01 \mathrm{M}$ Tris, and $1 \mathrm{mM}$ EDTA and incubated for $1 \mathrm{~h}$ at $37^{\circ} \mathrm{C}$. The sections were then washed in $2 \times \mathrm{SSC}$ at room temperature for $30 \mathrm{~min}$ and twice in $0.1 \times \mathrm{SSC}$ at $60^{\circ} \mathrm{C}$ for $30 \mathrm{~min}$. After dehydration in graded ethanol the slides were dipped in Kodak (Rochester, NY) NTB 2 emulsion diluted 1:1 with distilled water. Autoradiography was performed at $4^{\circ} \mathrm{C}$ for $3 \mathrm{wk}$. After development, sections were counterstained with hematoxylin and eosin. The hybridization signal was quantified by counting silver grains in the periportal or perivenous regions under bright-field illumination using a computer driven image analysis system (Seescan, Cambridge, UK). Specificity of hybridization was demonstrated using labeled sense RNA probes hybridized under identical conditions. No specific hybridization was seen with any sense probe (data not shown).

Statistics. All data are expressed as mean \pm SEM. Data were compared using an unpaired Student's $t$ tests or one-way ANOVA followed by a Newman-Keuls post-hoc multiple comparisons test where appropriate. Values were considered significant when $P<0.05$.

Table I. Effect of Dexamethasone on Offspring Body Weights

\begin{tabular}{cccc}
\hline Group & Birth weight & Weight at day 21 & Weight at 6 mo \\
\hline$g$ & $g$ & $g$
\end{tabular}

Control $\quad 6.2 \pm 0.1(n=27) \quad 47.3 \pm 3.3(n=11) 455.6 \pm 22.4(n=9)$ DEX WK1 $6.5 \pm 0.1(n=28) \quad 49.7 \pm 0.9(n=8) \quad 454.7 \pm 27.3(n=9)$ DEX WK2 $6.1 \pm 0.1(n=31) \quad 50.4 \pm 1.0(n=12) 458.5 \pm 18.2(n=13)$ DEX WK3 5.6 $\pm 0.1 *(n=33) 48.8 \pm 1.3(n=8) \quad 445.8 \pm 17.8(n=11)$

Body weights (grams) of the offspring of pregnant rats treated with vehicle alone (Control), DEX WK1, DEX WK2, or DEX WK3 were measured at birth, day 21 , and 6 mo. $* P<0.01$ compared with control.

\section{Results}

The effect of prenatal dexamethasone on offspring birth weight. Dexamethasone treatment did not affect maternal glucose levels, and there were no differences in length of gestation, litter size, or viability among the groups (data not shown). However, dexamethasone administration in the third week of pregnancy reduced offspring birth weight (treated 5.6 \pm 0.1 ; control $6.2 \pm 0.1 \mathrm{~g}, P=0.004)$. Treatment during the first or second week of gestation had no significant effects on birth weight (Table I). Body weights of all 3 dexamethasone-treated and control groups were similar at time of weaning (day 21 after birth) and at 6 mo (Table I).

The effect of prenatal dexamethasone treatment on glucose homeostasis. At 6 mo, offspring of dams that had dexamethasone during the last week of pregnancy had significantly higher fasting plasma glucose concentrations than controls $(5.3 \pm 0.3 \mathrm{vs}$. $4.3 \pm 0.2 \mathrm{mmol} /$ liter, $P=0.04)$. A randomly selected subset of each group was used for oral glucose tolerance tests. After an

(A)

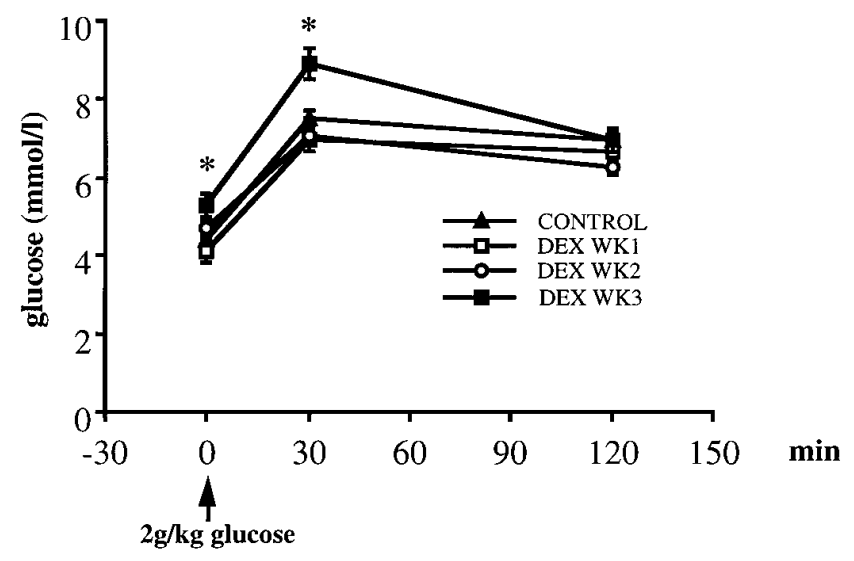

(B)

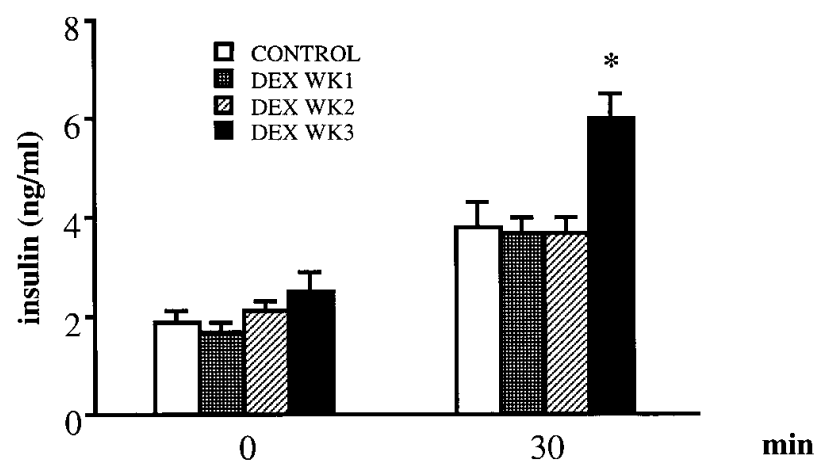

Figure 1. Plasma glucose and insulin responses to an oral glucose load in offspring. Offspring of pregnant rats that received vehicle alone $(C O N T R O L, n=9)$, DEX WK1 $(n=8)$, DEX WK2 $(n=13)$, or DEX WK3 $(n=8)$ underwent an oral glucose tolerance test at 6 mo. Plasma glucose $(A)$ was measured at 0,30 , and $120 \mathrm{~min}$ and insulin $(B)$ was measured at 0 and $30 \mathrm{~min}$ after oral glucose load. $* P<0.05$ compared to control. 
oral glucose load, DEX WK3 offspring had significantly higher 30-min plasma glucose concentrations compared to control $(8.7 \pm 0.4$ vs. $7.5 \pm 0.2 \mathrm{mmol} /$ liter, $P=0.03)$. There were no significant differences at $120 \mathrm{~min}$ (Fig. $1 A$ ). Fasting plasma insulin levels were similar in all the groups, but DEX WK3 offspring had higher 30-min insulin levels after glucose loading than controls $(6.1 \pm 0.4$ vs. $3.8 \pm 0.5 \mathrm{ng} / \mathrm{ml}, P=0.01)($ Fig. $1 B)$. DEX WK3 Offspring also showed an elevated 30-min insulinto-glucose ratio compared to controls $(0.71 \pm 0.06$ vs. $0.50 \pm 0.07$ $\mu \mathrm{g} / \mathrm{mmol}, P=0.03)$, suggesting more insulin secretion per unit of glucose. Dexamethasone administration during either the first or second week of gestation did not significantly affect glucose or insulin levels in the adult offspring.

The effect of prenatal dexamethasone treatment on $m R N A$ expression and activity of hepatic enzymes. Enzyme expression and activity was determined in livers of fed rats. Within the hepatic acinus, PEPCK mRNA expression was higher in the periportal zone than in the perivenous zone in all the groups. This zonation was age-dependent, with the perivenous-to-periportal (pv/pp) ratio increasing from 1:1.5 at birth and peaking to $1: 3$ by weaning. Dexamethasone administration during the first or second week of gestation significantly reduced periportal PEPCK mRNA expression in the offspring from birth up to $21 \mathrm{~d}$;
Day 1

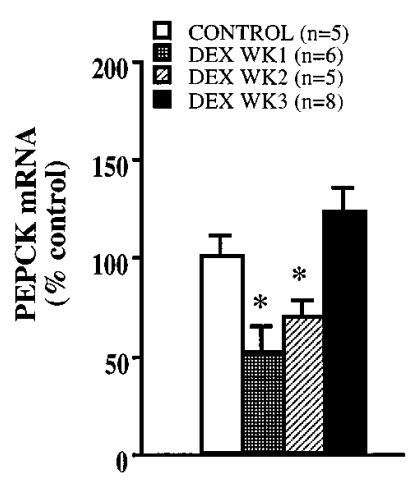

Day 21

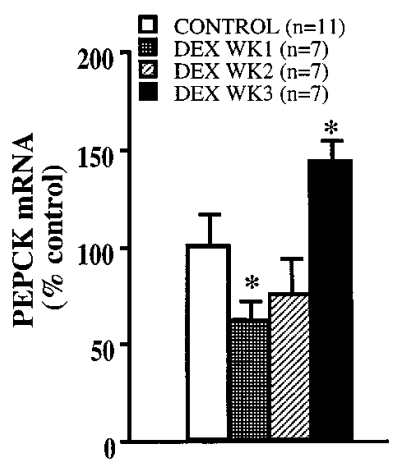

Day 5

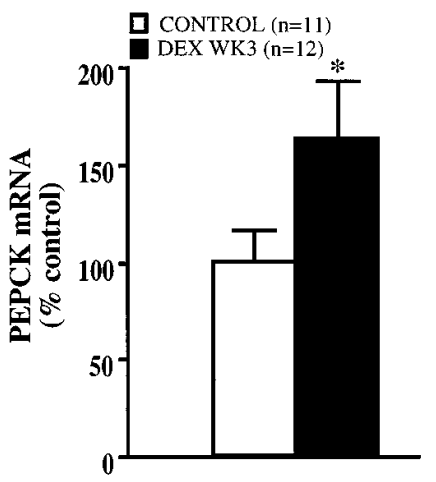

8 months

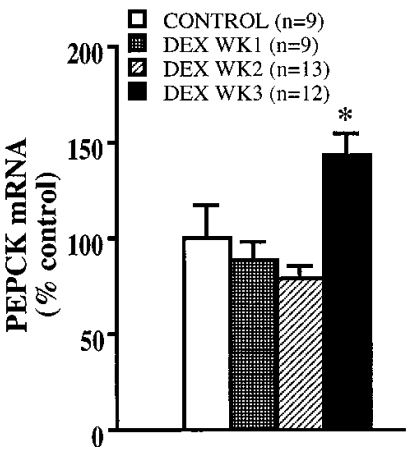

Figure 2. Effect of prenatal dexamethasone on periportal PEPCK mRNA expression in the offspring. Hepatic PEPCK mRNA expression in fed offspring of dams that received vehicle alone $(\mathrm{CON}$ TROL), DEX WK1, DEX WK2, or DEX WK3 was measured by in situ hybridization at days 1,5 , and 21 , and at 8 mo of age. Results represent periportal expression as a percentage of control. * $P<0.05$ compared to control.

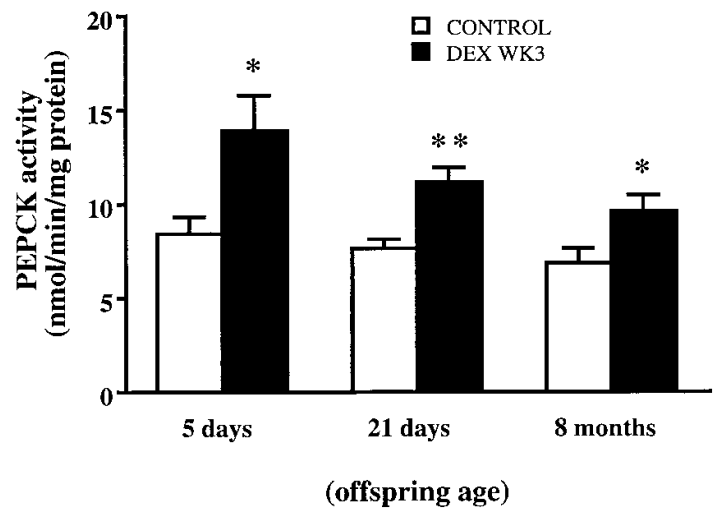

Figure 3. Effect of prenatal dexamethasone on hepatic enzyme activities. Activity of hepatic PEPCK was assayed in fed offspring (days 5 and 21 and at 8 mo of age) of dams that had vehicle alone (CON-

$T R O L)$ or DEX WK3. For controls, $n$ was 11,11 , and 9 at days 5 , and 21 and at 8 mo, respectively. For DEX WK3 $n$ was 12,7 , and 12 at days 5 , and 21 and at $8 \mathrm{mo}$, respectively). $* * P<0.01$, $* P<0.05$ compared with control.

at 8 mo expression was similar to control (Fig. 2). In contrast, treatment during the third week of pregnancy had no effect on PEPCK expression at birth but permanently increased periportal PEPCK expression from day 5 after birth onwards (Fig. 2). Perivenous PEPCK mRNA expression was not significantly affected by prenatal dexamethasone (data not shown). PEPCK enzyme activities were correspondingly increased in DEX WK3 offspring compared to controls (Fig. 3). Neither glucose-6-phosphatase nor glucokinase activity was affected by dexamethasone treatment (data not shown).

The effect of prenatal dexamethasone on hepatic GR expression. GR mRNA was widely expressed in the liver, with highest levels in the periportal region (pv/pp of 1:1.4). DEX WK3 offspring significantly elevated hepatic GR mRNA expression. (Fig. 4.). The increase in GR was maintained to adult life, but was more marked at day 5 after birth $(70 \%)$ than at 8 mo $(25 \%)$. The binding affinity of GR was unaltered by prenatal dexamethasone treatment (Table II).

The effect of prenatal dexamethasone on expression of hepatic $11 \beta$-HSD1. $11 \beta$-HSD1 was highly expressed in the liver. The distribution of $11 \beta$-HSD1 mRNA within the acini was similar to that of GR mRNA, with a pv/pp ratio of 1:1.3. Prenatal dexamethasone administration did not affect levels of expression or distribution of 11ß-HSD1 (Fig. 4.).

The effect of exogenous corticosterone on hepatic $G R$ expression. As hepatic GR mRNA was increased in animals that had dexamethasone late in pregnancy, we examined whether this was functionally important by measuring basal (8:30 a.m.) plasma corticosterone levels and by examining whether exogenous corticosterone modulated GR mRNA expression. There were no significant differences in basal plasma corticosterone levels between offspring of dams that had dexamethasone during the third week of pregnancy and controls ( $D E X W K 3$, $3.2 \pm 0.4$; Control, $2.5 \pm 0.6 P=0.4$ ). Exogenous corticosterone pellets did not affect the dissociation constant of hepatic GR (Table II), but significantly reduced expression of hepatic GR mRNA in DEX WK3 offspring (Fig. 5). The decrease in GR mRNA expression in controls did not reach statistical sig- 

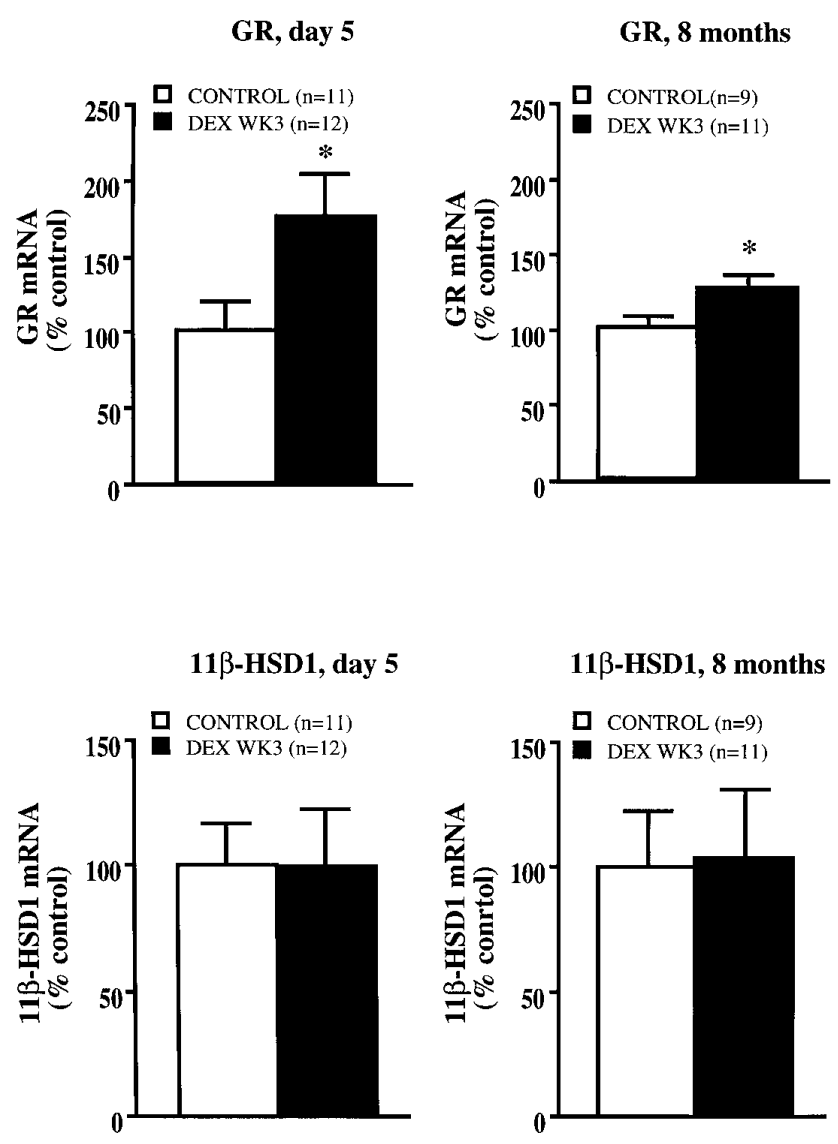

Figure 4. Effect of prenatal dexamethasone on periportal GR and $11 \beta$-HSD1 mRNA expression in the offspring. Hepatic GR and $11 \beta-$ HSD1 mRNA expression in fed offspring of dams that received vehicle alone (CONTROL) or DEX WK3 was measured by in situ hybridization at the ages of $5 \mathrm{~d}$ and $8 \mathrm{mo}$. Results are expressed as a percentage of periportal mRNA in control.

nificance. Even after exogenous corticosterone, GR mRNA expression in animals exposed to dexamethasone in utero remained higher than similarly treated controls (Fig. 5). Exogenous corticosterone significantly increased fasting plasma glu-

Table II. Hepatic GR Binding Affinity

\begin{tabular}{lccc}
\hline \multicolumn{1}{c}{ Group } & Kd Dex & Kd B & B max \\
\hline & $n M$ & $n M$ & $n$ nmol/g protein \\
Control+Sham & $4.5 \pm 0.4$ & $10.6 \pm 1.6$ & $0.29 \pm 0.05$ \\
Control+Cort & $5.3 \pm 0.4$ & $10.1 \pm 2.6$ & $0.24 \pm 0.03$ \\
DEX WK3+Sham & $4.4 \pm 0.8$ & $8.6 \pm 1.3$ & $0.37 \pm 0.07$ \\
DEX WK3+Cort & $5.1 \pm 0.7$ & $11.5 \pm 2.2$ & $0.26 \pm 0.04$ \\
& & & \\
\hline
\end{tabular}

Adult DEX WK3 offspring were given subcutaneous corticosterone pellets $(D E X W K 3+C o r t, n=6)$ or sham operated $(D E X W K 3+$ Sham, $n=6)$. Similarly, offspring of vehicle-treated dams received corticosterone pellets (Control + Cort, $n=6)$ or sham operation (Control + Sham, $n=6) .1$ wk after operation, GR binding affinity for ligand was determined on liver cytosols of fasted rats. Binding constants for dexamethasone $($ Dex $)$ and corticosterone $(B)$ were calculated from homologous and heterogous competition curves.

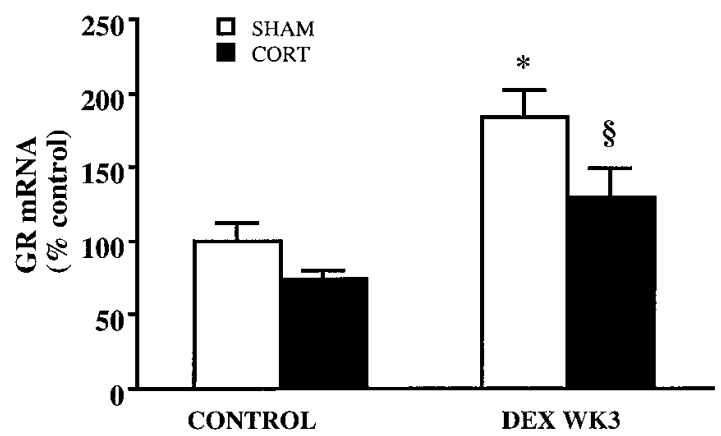

Figure 5. Effect of exogenous corticosterone on hepatic GR expression. Adult offspring of dams that had vehicle (CONTROL) or DEX WK3 were given subcutaneous corticosterone pellets $(C O R T)$ or sham operated (SHAM). $1 \mathrm{wk}$ after the operation, hepatic GR mRNA expression in fasted rats was measured by in situ hybridization. Results represent periportal mRNA expression as a percentage of control. $n=6$ per group. ${ }^{*} P<0.05$ for corticosterone vs. shamoperated in DEX WK 3 animals; ${ }^{\circledR} P<0.05$ for DEX vs. control in animals that had corticosterone.

cose levels in DEX WK3 offspring while levels in controls were unchanged (Fig. 6).

\section{Discussion}

We have shown that dexamethasone administration in the pregnant rat, selectively in the last week of gestation, reduces birth weight and produces fasting and postglucose hyperglycemia and hyperinsulinemia in the adult offspring. These findings are in accord with our earlier observations in which the physiological barrier to glucocorticoids, 11ß-HSD2, was inhibited by carbenoxolone throughout pregnancy (8), and directly demonstrate that prenatal exposure to elevated glucocorticoid levels programs glucose metabolism, leading to permanent hyperglycemia and apparent insulin resistance. The effect on both birth weight and glucose-insulin homeostasis of the off-

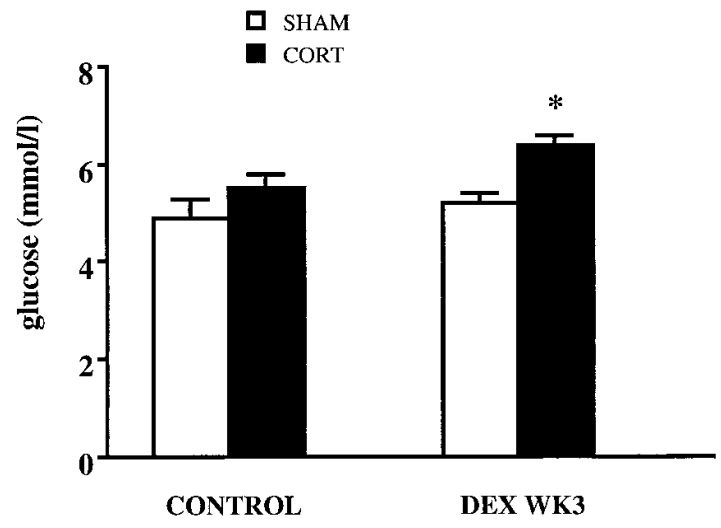

Figure 6. The effect of corticosterone pellets on fasting plasma glucose. Adult offspring of dams that had vehicle (CONTROL) or DEX WK3 were given subcutaneous corticosterone pellets $(C O R T)$ or sham operated (SHAM). Plasma glucose was measured on the third day after the operation, after an overnight fast. $n=6$ per group. $* P<$ 0.05 for corticosterone vs. sham-operated in DEX WK3 animals. 
spring only occurred when dexamethasone was administered during the third week of gestation and not earlier in pregnancy, suggesting a late gestational window of sensitivity to glucocorticoids. The nature of the late period of sensitivity to glucocorticoids is uncertain; GR are expressed in many tissues, including liver, from midgestation onwards (32). Perhaps the congruence of rapid growth in late gestation with the expression of key glucocorticoid-regulated growth factors, such as the insulin-like growth factor (IGF) system, may be of importance. Indeed hepatic production of IGF binding protein-1 (IGFBP-1), which neutralizes the actions of IGF-1, is markedly induced in late gestation fetuses by high-dose maternal dexamethasone treatment (33), and has been advocated as causal in the growth retardation observed. Furthermore, transgenic mice overexpressing IGFBP-1 have low birth weight and adult hyperglycemia (34), perhaps suggesting one mechanism through which glucocorticoids link low birth weight and abnormal glucose metabolism. However, these programming mechanisms are likely to be complex because GR mediates its effects by interacting with several factors. For example, regulation of IGFBP-1 by glucocorticoids involves interaction of GR with hepatic nuclear factor-1 (35), which has been causally linked to diabetes (36). Whatever the mechanisms, the effects of late prenatal glucocorticoids mimic, and might therefore underlie, the human epidemiological associations between low birth weight and later glucose intolerance/NIDDM.

The basis of NIDDM is incompletely understood, but increased hepatic glucose production may be a major contributing factor (37). In adult life, glucocorticoids affect glucoseinsulin homeostasis at several levels, by inducing peripheral insulin resistance (38), inhibiting insulin secretion (39), and stimulating gluconeogenesis (37). In early life, glucocorticoids exert important maturational effects on enzymes involved in glucose metabolism, most notably PEPCK $(13,14,40)$. Our results show that treatment with dexamethasone during the third week of pregnancy induces permanent overexpression of PEPCK in the offspring, with no effect on glucose-6-phosphatase (another gluconeogenic enzyme) or glucokinase (a glycolytic enzyme), though the decline in the latter approached significance. The effects on PEPCK were transcriptional, in accord with the predominant level of control of this gene product, and were specifically confined to periportal regions, the major sites of gluconeogenesis in the hepatic acinus. Selective increases in gluconeogenic enzyme activity have been documented in various animal models of NIDDM (41, 42). Since PEPCK is the rate limiting enzyme of gluconeogenesis (43), and overexpression of PEPCK in a rat hepatoma cell line impairs suppression of gluconeogenesis (44), it is plausible that increased PEPCK in vivo potentiates hepatic glucose production, producing the observed glucose intolerance. Indeed, transgenic mice overexpressing PEPCK have impaired glucose tolerance (45).

The mechanism by which PEPCK expression is increased by exposure to dexamethasone in utero is unclear. In the adult rat liver, PEPCK gene transcription is increased by glucocorticoids, glucagon (through cAMP), thyroid hormone and retinoic acid, and is negatively and dominantly regulated by insulin $(46,47)$. The PEPCK gene promoter has two distinct cis elements which are bound by activated GR (48). PEPCK appears in liver with the first lactational feed on the day of birth (49), and is associated with the increase in glucagon-to-insulin ratio (50) and/or the rise in glucocorticoids (40) that occurs at this time. Indeed PEPCK can be induced prematurely by injection of glucagon (51, 52), cAMP (49), and glucocorticoids, at least in the chick (53) and sheep (40). However, in this study dexamethasone in the last week of pregnancy did not alter PEPCK expression at birth, but only from day 5, suggesting an indirect effect. The actions of glucocorticoids in the liver are modulated by $11 \beta-H S D 1$ which amplifies intrahepatic glucocorticoid action by catalyzing the conversion of the ample supply of inert circulating metabolites (cortisone and 11-dehydrocorticosterone) into bioactive glucocorticoids (cortisol and corticosterone) (54). Indeed, mice with targeted disruption of the $11 \beta$-HSD1 gene show deficient induction of gluconeogenic enzymes (55). However, 11 $\beta$-HSD1 expression was unaltered by prenatal dexamethasone, and was not enriched periportally, providing no support for this idea.

In contrast, prenatal dexamethasone permanently increased GR expression in the liver. The increase in hepatic GR mRNA expression occurred in the presence of maintained (i.e., unsuppressed) circulating glucocorticoids and unaltered GR binding affinity for ligand. This is an intriguing finding, since GR mRNA levels are often negatively autoregulated by circulating glucocorticoids (56). Indeed exogenous corticosterone administration achieved some downregulation of GR mRNA in these animals. However, hepatic GR levels in animals exposed to dexamethasone in utero remained higher than similarly treated controls. This finding suggests that glucocorticoids are able to downregulate GR in offspring of dexamethasonetreated dams, but that the basal set point of hepatic GR expression is higher compared to controls. Several, possibly species-specific, molecular mechanisms of regulation of GR expression have been suggested. In the mouse GR expression is controlled by at least three promoters, one of which is preferentially used in T lymphocytes (57). Rat mRNA also shows high variability at the $5^{\prime}$ end, suggesting expression from different transcriptional start sites and/or promoters (58). The rise in hepatic GR mRNA expression in offspring that were exposed to dexamethasone in utero, may well reflect induction of a liver-specific promoter, since GR mRNA is decreased by the same treatment in hippocampal neurons (18). Increased hepatic GR expression, in the presence of maintained corticosterone levels and unaltered GR binding affinity, suggests that prenatal dexamethasone may program enhanced glucocorticoid mediated responses, such as induction of hepatic PEPCK expression. This contention is supported by the increased blood glucose sensitivity which these rats show to exogenous glucocorticoids. The lack of effect on other glucocorticoid-sensitive mRNAs and enzymes may well reflect the complex control of these gene products.

Fetal nutrition is also important in determining prenatal growth and maternal lack of nutrition is associated with later disease, including hypertension and diabetes (2). Specifically, maternal protein restriction during rat pregnancy produces offspring showing hypertension and hyperglycemia, with altered hepatic enzyme profiles including increased PEPCK activity (59). It is possible that the effects of glucocorticoids and lack of nutrition have a common underlying mechanism. Indeed maternal protein restriction during rat pregnancy attenuates placental $11 \beta$-HSD2 activity (60), suggesting that excessive glucocorticoid exposure may mediate, in part, the effects of a lack of nutrition. Moreover, hypertension induced by a maternal low-protein diet in the rat is prevented by inhibitors of glucocorticoid synthesis (61). Thus, fetal overexposure to 
glucocorticoids may represent a common link between the maternal environment, fetal growth, and later cardiovascular and metabolic diseases, notably NIDDM.

\section{Acknowledgments}

We thank Val Lyons, Susan Nelson, and Pamela Houston for their excellent technical assistance, and Drs. Dieter Schmoll, Günther Schütz, Carl Monder, Perrin White, and Roger Miesfeld for cDNA clones.

These studies were supported by a Wellcome Senior Clinical Research Fellowship (Jonathan R. Seckl) and a Program Grant from the Wellcome Trust. Moffat J. Nyirenda is the recipient of an Overseas Research Studentship and a World Health Organization fellowship.

\section{References}

1. Barker, D.J.P., P.D. Gluckman, K.M. Godfrey, J.E. Harding, J.A. Owens, and J.S. Robinson. 1993. Fetal nutrition and cardiovascular disease in adult life. Lancet. 341:938-941.

2. Valdez, R., M.A. Athens, G.H. Thompson, B.S. Bradshaw, and M.P. Stern. 1994. Birth weight and adult health outcomes in a biethnic population in the USA. Diabetologia. 37:624-631.

3. Barker, D.J.P., A.R. Bull, C. Osmond, and S.J. Simmonds. 1990. Fetal and placental size and risk of hypertension in adult life. Br. Med. J. 301:259-263.

4. Hales, C.N., D.J.P. Barker, P.M.S. Clark, L.J. Cox, C. Fall, C. Osmond, and P.D. Winter. 1991. Fetal and infant growth and impaired glucose tolerance at age 64. Br. Med. J. 303:1019-1022.

5. McCance, D., D. Pettitt, R. Hanson, L. Jacobsson, W. Knowler, and P. Bennett. 1994. Birthweight and non-insulin-dependent diabetes: thrifty genotype, thrifty phenotype, or surviving small baby genotype? Br. Med. J. 308:942-945.

6. Hales, C.N., and D.P.J. Barker. 1992. Type 2 (non-insulin-dependent) diabetes mellitus: the thrifty phenotype hypothesis. Diabetologia. 35:595-601.

7. Purdy, L.P., and B.E. Metzger. 1996. Influences of intrauterine metabolic environment on adult disease: what may we infer from size at birth? Diabetologia. 39:1126-1130.

8. Lindsay, R.S., R.M. Lindsay, B.J. Waddell, and J.R. Seckl. 1996. Prenatal glucocorticoid exposure leads to hyperglycaemia in the rat: studies with $11 \beta$ hydroxysteroid dehydrogenase inhibitor carbenoxolone. Diabetologia. 39:12991305.

9. Edwards, C.R.W., R. Benediktsson, R. Lindsay, and J.R. Seckl. 1993. Dysfunction of the placental glucocorticoid barrier: a link between the foetal environment and adult hypertension? Lancet. 341:355-357.

10. Ross, E., P. Marshall-Jones, and M. Friedman. 1966. Cushing's syndrome: diagnostic criteria. Q. J. Med. 35:149-193.

11. Reinisch, J.M., N.G. Simon, W.G. Karow, and R. Gandleman. 1978. Prenatal exposure to prednisone in humans and animals retards intrauterine growth. Science. 202:436-438.

12. Goland, R.S., S. Josak, W.B. Warren, I.M. Conwell, R.I. Stark, and P.J. Tropper. 1993. Elevated levels of umbilical cord plasma corticotrophin-releasing hormone in growth-retarded fetuses. J. Clin. Endocrinol. Metab. 77:11741179.

13. Ballard, P.L. 1979. Glucocorticoids and differentiation. In Glucocorticoid Hormone Action (Monographs in Endocrinology). J.D. Baxter and G.G. Rousseau, editors. Springer-Verlag, Berlin. 493-497.

14. Liggins, G.C. 1976. Adrenocortical-related maturational events in the fetus. Am. J. Obstet. Gynecol. 126:931-939.

15. Harris, G. 1964. Sex hormones, brain development, and brain function. Endocrinology. 75:627-648.

16. Gustafsson, J.A., and A. Sternberg. 1974. Neonatal programming of androgen responsiveness of liver of adult rats. J. Biol. Chem. 249:719-723.

17. Meaney, M.J., D.H. Aitken, C. van Berkel, S. Bhatnagar, and R.M. Sapolsky. 1988. Effect of neonatal handling on age-related impairments associated with the hippocampus. Science. 239:766-768.

18. Levitt, N.S., R.S. Lindsay, M.C. Holmes, and J.R. Seckl. 1996. Dexamethasone in the last week of pregnancy attenuates hippocampal glucocorticoid receptor gene expression and elevates blood pressure in the adult offspring in the rat. Neuroendocrinology. 64:412-418.

19. Friedman, J.E., J.S. Yun, Y.M. Patel, M.M. McGrane, and R.W. Hanson. 1993. Glucocorticoids regulate the induction of phosphoenolpyruvate carboxykinase (GTP) gene expression during diabetes. J. Biol. Chem. 268:1295212957.

20. Brown, R.W., K.E. Chapman, Y. Kotolevtsev, J. Yau, R.S. Lindsay, L. Brett, C. Leckie, P. Murad, V. Lyons, J. Mullins, et al. 1996. Cloning and production of antisera to human placental $11 \beta$-hydroxysteroid dehydrogenase type 2. Biochem. J. 313:1007-1017.

21. Murphy, B.E.P., S.J. Clark, I.R. Donald, M. Pinsky, and D.L. Vedady.
1974. Conversion of maternal cortisol to cortisone during placental transfer to the human fetus. Am. J. Obstet. Gynecol. 118:538-541.

22. Stewart, P., F. Rogerson, and J. Mason. 1995. Type 2 11ß-hydroxysteroid dehydrogenase messenger RNA and activity in human placenta and fetal membranes: its relationship to birth weight and putative role in fetal steroidogenesis. J. Clin. Endocrinol. Metab. 80:885-890.

23. MacPhee, I.A.M., F.A. Antoni, and D.W. Mason. 1989. Spontaneous recovery of rats from experimental allergic encephalomyelitis is dependent on regulation of the immune system by endogenous adrenal corticosteroids. $J$. Exp. Med. 169:431-445.

24. Panarelli, M., C.D. Holloway, A.B.P. Barr, R. Fraser, and C.J. Kenyon. 1995. Differences in temperature-sensitive receptor binding of glucocorticoids in spontaneously hypertensive and normotensive wistar Kyoto (WKY) rats. Steroids. 60:73-75.

25. Peterson, G.L. 1977. A simplification of the protein assay method of Lowry et al. which is more generally applicable. Anal. Biochem. 83:346-356.

26. Petrescu, I., O. Bojan, M. Saied, O. Barzu, F. Schmidt, and H.F. Kuhnle. 1979. Determination of phosphoenolpyruvate carboxykinase activity with deoxyguanine 5'-diphosphate as a nucleotide substrate. Anal. Biochem. 96:279-281.

27. Davidson, A.L., and W.J. Arion. 1987. Factors underlying significant underestimations of glucokinase activity in crude liver extracts: physiological implications of higher cellular activity. Arch. Biochem. Biophys. 253:156-167.

28. Burchell, A., R. Hume, and B. Burchell. 1988. A new microtechnique for analysis of the human hepatic microsomal glucose-6-phosphatase system. Clin. Chim. Acta. 173:183-192.

29. Miesfeld, R., S. Okret, A.C. Wikstrom, and K.R. Yamamoto. 1984. Characterization of a steroid hormone receptor gene and mRNA in wild type and mutant cells. Nature. 312:779-781.

30. Agarwal, A.K., C. Monder, B. Eckstein, and P.C. White. 1989. Cloning and expression of rat cDNA encoding corticosteroid 11 beta-dehydrogenase. $J$. Biol. Chem. 264:18939-18943.

31. Seckl, J.R., K. Dickson, and G. Fink. 1990. Central 5,7-dihydroxytryptamine lesions decrease hippocampal glucocorticoid and mineralocorticoid receptor messenger ribonucleic acid expression. J. Neuroendocrinol. 2:919-926.

32. Cole, T.J., J.A. Blendy, A.P. Monaghan, W. Schmid, A. Aguzzi, and G. Schutz. 1995. Molecular genetic analysis of glucocorticoid signaling during mouse development. Steroids. 60:93-96.

33. Price, W.A., A.D. Stiles, B.M. Moats-Staats, and A.J. D'Ercole. 1992. Gene expression of the insulin-like growth factors (IGFs), the type 1 IGF receptor, and IGF-binding proteins in dexamethasone-induced fetal growth retardation. Endocrinology. 130:1424-1432.

34. Rajkuhmar, K., D. Barron, M.S. Lewitt, and L.J. Murphy. 1995. Growth retardation and hyperglycemia in insulin-like growth factor binding protein 1 transgenic mice. Endocrinology. 136:4029-4034.

35. Suh, D.S., and M.M. Rechler. 1997. Hepatic nuclear factor 1 and glucocorticoid receptor synergistically activate transcription of the rat insulin-like growth factor binding protein-1 gene. Mol. Endocrinol. 11:1822-1831.

36. Yamagata, K., N. Oda, P.J. Kaisaki, S. Menzel, H. Furuta, M. Vaxillaire, L. Southam, R.D. Cox, G.M. Lathrop, V.V. Boriraj, et al. 1996. Mutations in the hepatocyte nuclear factor 1-alpha gene in maturity-onset diabetes of the young (MODY 3). Nature. 384:455-458.

37. Consoli, A., N. Nurjhan, J.J. Reilly, Jr., D.M. Beir, and J.E. Gerich. 1990. Mechanism of increased gluconeogenesis in non-insulin-dependent diabetes mellitus. Role of alterations in systemic, hepatic, and muscle lactate and alanine metabolism. J. Clin. Invest. 86:2038-2045.

38. Weinstein, S.P., T. Paquin, A. Pritsker, and R.S. Haber. 1995. Glucocorticoid-induced insulin resistance: dexamethasone inhibits the activation of glucose transport in rat skeletal muscle by both insulin- and non-insulin-related stimuli. Diabetes. 44:441-445.

39. Lambillotte, C., P. Gilon, and J.-C. Henquin. 1997. Direct glucocorticoid inhibition of insulin secretion. An in vitro study of dexamethasone effects in mouse islets. J. Clin. Invest. 99:414-423.

40. Fowden, A.L., J. Mijovic, and M. Silver. 1993. The effects of cortisol on hepatic and renal gluconeogenic enzyme activities in the sheep fetus during late gestation. J. Endocrinol. 137:213-222.

41. Chang, A.Y., and D.I. Schneider. 1970. Abnormalities in hepatic enzyme activities during development of diabetes in db/db mice. Diabetologia. 6 274-278.

42. Taketomi, S., M. Tsuda, T. Matsuo, H. Iwatsuka, and Z. Suzuoki. 1973. Alterations of hepatic enzyme activities in $\mathrm{KK}$ and yellow $\mathrm{KK}$ in various diabetic states. Horm. Metab. Res. 7:242-246.

43. Pilkis, S.J., and D.K. Granner. 1992. Molecular physiology of regulation of hepatic gluconeogenesis and glycolysis. Annu. Rev. Physiol. 54:885-909.

44. Rosella, G., J.D. Zajac, S.J. Kaczmarczyk, S. Adrikopoulos, and J. Proietto. 1993. Impaired suppression of gluconeogenesis induced by overexpression of noninsulin-responsive phosphoenolpyruvate carboxykinase gene. Mol. Endocrinol. 7:1456-1462.

45. Valera, A., A. Pujol, M. Pelegrin, and F. Bosch. 1994. Transgenic mice overexpressing phosphoenolpyruvate carboxykinase develop non-insulin-dependent diabetes. Proc. Natl. Acad. Sci. USA. 91:9151-9154.

46. O’Brien, R.M., and D.K. Granner. 1991. Regulation of gene expression by insulin. Biochem. J. 278:609-619. 
47. Lucas, P.C., and D.K. Granner. 1992. Hormone response domains in gene transcription. Annu. Rev. Biochem. 61:1131-1173.

48. Imai, E., P.E. Stromstedt, P.G. Quinn, J. Carlstedt-Duke, J.A. Gustafsson, and D.K. Granner. 1990. Characterization of a complex glucocorticoid response unit in the phosphoenolpyruvate carboxykinase gene. Mol. Cell. Biol. 10:4712-4719.

49. Ballard, F.J., and R.W. Hanson. 1967. Phosphoenolpyruvate carboxykinase and pyruvate carboxylase in the developing rat liver. Biochem. J. 104:866-871.

50. Girard, J. 1989. Control of fetal and neonatal glucose metabolism by pancreatic hormones. Bailliére's Clin. Endocrin. Metab. 3:817-836.

51. Phillippiddis, H., and F.J. Ballard. 1970. The development of gluconeogeneis in rat liver. Effects of glucagon and ether. Biochem. J. 120:385-392.

52. Ruiz, J.P.G., R. Ingram, and R.W. Hanson. 1978. Changes in hepatic messenger RNA for phosphoenolpyruvate carboxykinase (GTP) during development. Proc. Natl. Acad. Sci. USA. 75:4189-4193.

53. McCaffrey, J., and J.W. Hamilton. 1993. Developmental regulation of basal and hormone-inducible phosphoenolpyruvate carboxykinase gene expression in chick embryo liver in vivo. Arch. Biochem. Biophys. 309:10-17.

54. Jamieson, P.M., K.E. Chapman, C.R.W. Edwards, and J.R. Seckl. 1995. $11 \beta$-hydroxysteroid dehydrogenase is an exclusive $11 \beta$-reductase in primary cultures of rat hepatocytes: effect of physicochemical and hormonal manipulations. Endocrinology. 136:4754-4761.

55. Kolelevtsev, Y., M.C. Holmes, A. Burchell, P.M. Houston, D. Schmoll,
P. Jamieson, R. Best, R. Brown, C.R.W. Edwards, J.R. Seckl, et al. 1997. 11 $\beta$-hydroxysteroid dehydrogenase type 1 knockout mice show attenuated glucocorticoid-inducible responses and resist hyperglycemia on obesity or stress. Proc. Natl. Acad. Sci. USA. 94:14924-14929.

56. Schmidt, T.J., and A.S. Meyer. 1994. Autoregulation of corticosteroid receptors. How, when, where, and why? Receptor. 4:229-252.

57. Strahle, U., A. Schmid, G. Kelsey, A.F. Stewart, T.J. Cole, W. Schmid, and G. Schutz. 1992. At least three promoters direct expression of mouse glucocorticoid receptor gene. Proc. Natl. Acad. Sci. USA. 89:6731-6735.

58. Gearing, K.L., W. Cairns, S. Okren, and J.A. Gustafsson. 1993. Heterogeneity in the $5^{\prime}$ untranslated region of the rat glucocorticoid receptor mRNA J. Steroid Biochem. Mol. Biol. 46:635-639.

59. Desai, M., N.J. Crowther, S.E. Ozanne, A. Lucas, and C.N. Hales. 1995. Adult glucose and lipid metabolism may be programmed during fetal life. Biochem. Res. Trans. 23:331-335.

60. Langley-Evans, S.C., G. Philips, R. Benediktsson, D. Gardner, C.R.W Edwards, A.A. Jackson, and J.R. Seckl. 1996. Maternal dietary protein restriction, placental glucocorticoid metabolism, and the programming of hypertension. Placenta. 17:169-172.

61. Langley-Evans, S.C. 1997. Hypertension induced by foetal exposure to maternal low-protein diet, in the rat, is prevented by pharmacological blockade of maternal glucocorticoid synthesis. J. Hypertens. 15:537-544. 